\title{
An Investigation on the Migration and Settlement Law of Temporary Plugging Particles in Horizontal Wellbore
}

\author{
Yao Luo, ${ }^{1}$ Hao Lang, ${ }^{2}$ Dan Yang, ${ }^{1}$ Xianli Wen, ${ }^{1}$ Jianshe Guo, ${ }^{3,4}$ Hui Kong, ${ }^{1}$ Xue Meng, \\ Shaobo Han, ${ }^{2}$ and Fujian Zhou (ii) ${ }^{2}$ \\ ${ }^{1}$ Engineering Technology Research Institute of Xinjiang Oilfield Company, Karamay 83400, China \\ ${ }^{2}$ China University of Petroleum (Beijing), Institute of Unconventional Oil and Gas Science and Technology, Beijing 102249, China \\ ${ }^{3}$ Northeast Petroleum University, Daqing City 163318, China \\ ${ }^{4}$ Tuha Oilfield Company, CNPC, Turpan 838202, China
}

Correspondence should be addressed to Fujian Zhou; zhoufj@cup.edu.cn

Received 7 October 2021; Revised 26 October 2021; Accepted 27 October 2021; Published 29 November 2021

Academic Editor: Wei Yu

Copyright (c) 2021 Yao Luo et al. This is an open access article distributed under the Creative Commons Attribution License, which permits unrestricted use, distribution, and reproduction in any medium, provided the original work is properly cited.

Migration and settlement of temporary plugging particles of different sizes affect the effect of temporary plugging, which in turn affect the effect of reservoir reconstruction. However, the migration and settlement laws of temporary plugging particles in horizontal wellbore are still unclear. In order to study the migration and settlement laws of temporary plugging particles in horizontal wellbore, a set of multicluster perforation physical model experiment device for horizontal wells was built. Based on this experimental device, the effects of mass ratio, pumping rate, and adding sequence on the migration and settlement laws of temporary plugging particles were studied, respectively. The experimental results show that the $3 \mathrm{~mm}$ temporary plugging particles move forward in a leaping manner at the bottom of the horizontal wellbore and the $1 \mathrm{~mm}$ particles are distributed in layers in the horizontal wellbore, and the particles are less in the upper part of the wellbore and more in the bottom of the wellbore. The migration trajectory of the two mixed particles is similar to the single. Under different mass ratio, the settlement mass of particles in the perforation clusters at the outlet end is greater than that in the entrance end. When the $3 \mathrm{~mm}$ particles account for a relatively large amount $\left(m_{3 \mathrm{~mm}}: m_{1 \mathrm{~mm}}=5: 1\right)$, the settlement mass of the particles in the two perforation clusters is greater than other mass ratio conditions. For the same perforation, the settlement mass becomes greater as the proportion of $3 \mathrm{~mm}$ increases. When only $3 \mathrm{~mm}$ particles are considered, with the increasing of displacement, the mass of particles in the perforation clusters at the inlet end increases, and the mass of particles in the clusters at the outlet end decreases. With the increase of displacement, the sedimentation mass of particles in high angle perforations decreases, while the sedimentation mass in other perforations increases. Adding $3 \mathrm{~mm}$ first and then $1 \mathrm{~mm}$ particles, the particle settlement mass in the perforation cluster at the outlet end is twice the mass of the particles in the perforation cluster at the inlet end. Reversing the sequence, the settlement masses of the particles in the two clusters are almost equal. The particle distribution in the perforation at different angles has obvious gradation. The smaller the angle, the greater the settlement mass of the temporary plugging particles. This research results will provide reference for temporary plugging and fracturing construction.

\section{Introduction}

The tight reservoirs generally have the characteristics of the poor physical properties and low production, so the fracturing is needed for production [1-4]. However, the reservoir reconstruction needs temporary plugging and fracturing, and good temporary plugging particles are of great significance to the temporary plugging and turning of hydraulic fractures [5]. During the pumping process of temporary plugging particles, particles migrate and settle in the horizontal wellbore, which ultimately affects the plugging effect. Therefore, it is necessary to study the law of particles migration and settlement in horizontal wellbore.

Regarding the migration and settlement of temporary plugging particles in the wellbore, there are few publications at home and abroad. Therefore, we can draw lessons from 
other researches, such as proppant, and provide reference for the study of the migration and settlement law of temporary plugging particles in horizontal wellbore. The laboratory experiment is one of the important means to investigate the migration and settlement laws of temporary plugging particles and can directly observe the migration and settlement of temporary plugging particles in the wellbore. Scholars at home and abroad have done a lot of research on the migration and settlement of proppant. Since 1960s, Stokes [6] has studied the free settlement law of a single particle in an ideal state, deduced the relationship between the drag coefficient and Reynolds number according to Reynolds number, established the particle settlement model of Newtonian fluid in different flow regimes, and also studied the settlement law of the proppant in nonNewtonian fluid. The distribution of the proppant during horizontal well fracturing was studied [7-10]. These experiments considered the influence of almost all construction parameters. The critical settlement and suspension velocity were recalculated, and the relevant formulas were given. $\mathrm{Xu}$ and Zhou [11] studied the influence of proppant, fracturing fluid properties, pipe sizes, and radius of curvature on the critical settlement velocity based on the existing proppant settlement laws and other experimental laws and obtained a new formula for calculating the critical settlement velocity. Hannah et al. [12] used a concentric circle device to analyze the settlement velocity of the proppant. Among them, the focus was on the impact of cylinder wall, concentration, and shear on non-Newtonian and Newtonian fluids. He thought that a more in-depth analysis of the settlement velocity of non-Newtonian fluids under shear will be of great significance. Harrington et al. [13] and Novotny [14] et al. studied the proppant settlement in two fluids, noncrosslinked and cross-linked. It was found that in the crosslinked gel, the error between the research results and the settlement velocity calculated by Stokes' law was very obvious. At the same time, Clark et al. [15] and [16] pointed out that the results obtained by using the parallel device and the concentric device and the settlement velocity calculated by Stokes' law also had significant errors. [17] gave the influence of fracture size and proppant concentration on the overall migration law of proppant and found that the larger the proppant particles and the higher the concentration, the slower the migration speed. Mei et al. (2006) investigated the particle migration, deposition, and plugging mechanism in the porous media, network model, the interconnected pore, and throat network on the basis of reservoir pore structure, which was applied to the optimization of temporary plugging particles in the temporary plugging techniques. Bokane et al. [18] and Jain [19] et al. studied the effects of pumping displacement and perforation clusters on the proppant migration through horizontal wellbore proppant diversion experimental devices. Ngameni [20] used a self-developed horizontal wellbore simulation device to study the effect of perforation clusters on proppant migration. Zhang et al. [21] established the Euler-Euler two-phase flow model to study the transport and settlement behavior of proppant during clean water fracturing and studied the flow law of proppant under different inlet velocity and position, sand density, and other parameters. Zhang [22] conducted an experimental study on the sedimentation behavior of single particle proppant in slickwater fracturing fluid on the basis of considering the sedimentation law of solid particles. Pan et al. [23] studied the influence of pumping displacement, liquid viscosity, and proppant particle size on the proppant migration by using a horizontal transparent wellbore containing multiple clusters of perforations. Mao et al. [24] studied proppant delivery under real-scale pumping plans (multisize proppants and different concentrations) on site scale and quantitatively evaluated the impact of proppant plans on the production of slickwater fractured wells. However, it can be found that no publications have discussed the migration and settlement of temporary plugging particles in horizontal wellbore. In this paper, we will further study this issue.

Based on the above discussion, the migration and settlement laws of temporary plugging particles in horizontal wellbore are still unclear. In the paper, based on the selfbuilt visual horizontal wellbore, we investigated the migration and settlement of particles in the horizontal wellbore. First, we set up a visual wellbore for studying particle migration and settlement. Second, we studied the migration law of particles with different sizes in horizontal wellbore when they exist alone or mixed. Third, under that condition that particles with different sizes are combined according to different mass ratio, the law of particles entering the perforations (clusters) was studied. Subsequently, we discussed the mass of particles settled in different perforations (clusters) under different pumping displacements. Finally, by changing the adding order of particles with different sizes, we investigated the settlement laws of particles in different perforations (clusters).

\section{Experiment Preparation}

2.1. Visualized Migration Experiment. We injected the prepared carrier liquid into the liquid storage tank in advance, pumped the carrier liquid into the visual artificial horizontal wellbore by using the sediment submersible pump, and waited for the liquid to fill the wellbore and stabilize. Then, different types of temporary plugging particles were added and fully stirred. Under different conditions, the migration and settlement of particles in the horizontal wellbore and perforations were different.

Maintain the pumping state and observe the migration trajectory of temporary plugging particles in horizontal wellbore through visual wellbore model; at the same time, the settlement mass of temporary plugging particles in each perforation or cluster is counted. Through the quantitative analysis of the experimental results, the migration and settlement laws of temporary plugging particles in the horizontal wellbore are obtained.

2.2. Experimental Device. The experimental device consists of a liquid storage tank, an electric submersible pump, a visualized horizontal wellbore, a frequency converter, and a stirring rod, as shown in Figures 1(a) and 1(b). Among them, the storage tank has a volume of $0.1 \mathrm{~m}^{3}$. The 


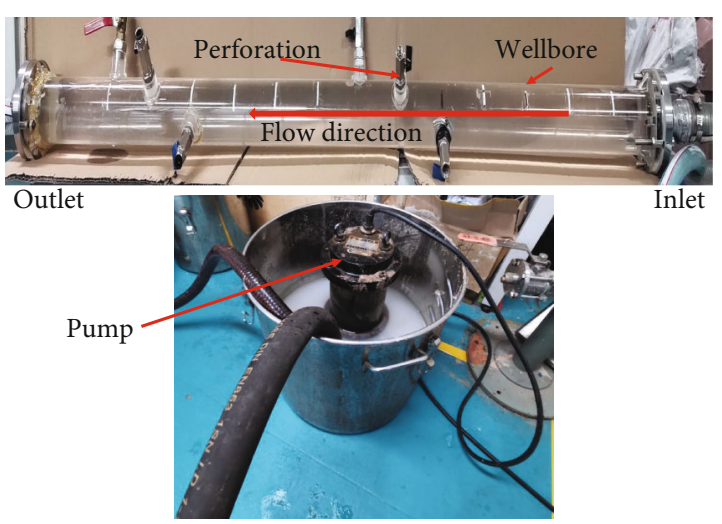

(a) The actual experimental device

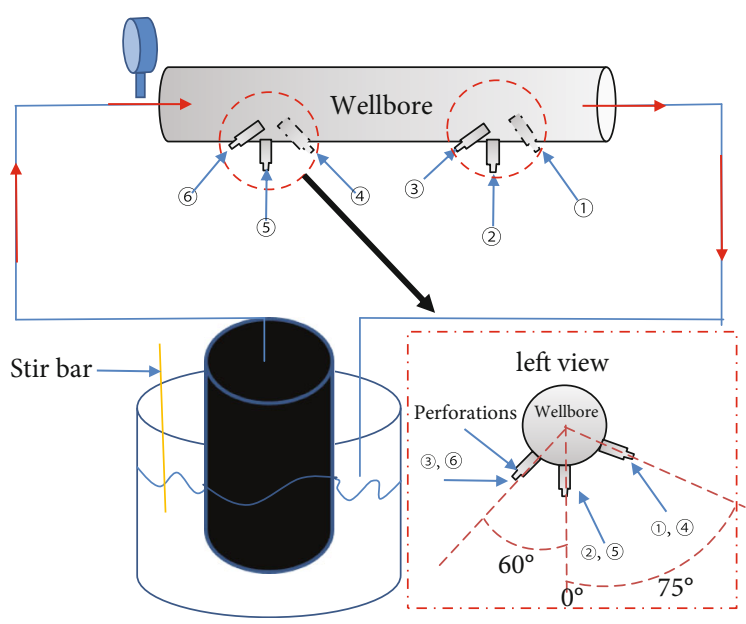

(b) The schematic diagram

Figure 1: Settlement and differentiation simulation device for particle in wellbore.

maximum displacement of the electric submersible pump is $0.11 \mathrm{~m}^{3} \cdot \mathrm{min}^{-1}$, its frequency is adjustable, and the maximum frequency is $50 \mathrm{~Hz}$. All experimental displacements in the article are $0.11 \mathrm{~m}^{3} \cdot \mathrm{min}^{-1}, 0.10 \mathrm{~m}^{3} \cdot \mathrm{min}^{-1}, 0.09 \mathrm{~m}^{3} \cdot \mathrm{min}^{-1}$, and $0.08 \mathrm{~m}^{3} \cdot \mathrm{min}^{-1}$, respectively. The angles of the perforations (P) 2 and 5 are $0^{\circ}$, the angles of $\mathrm{P} 1$ and $\mathrm{P} 4$ are $75^{\circ}$, and the angles of $\mathrm{P} 3$ and $\mathrm{P} 6$ are $60^{\circ}$. Especially, we designate P1, $\mathrm{P} 2$, and $\mathrm{P} 3$ at the outlet as cluster 2 (C2), and P4, P5, and P6 at the inlet as cluster $1(\mathrm{C} 1)$. The detailed parameters of the device are shown in Table 1.

2.3. The Experimental Materials. The temporary plugging particles are independently developed by the laboratory. The temporary plugging particles used in the experiment are copolymers of lactic acid and glycolic acid. The particle size of the temporary plugging particles is $3 \mathrm{~mm}$ and $1 \mathrm{~mm}$ (Figure 2), and the particle density is $1.0-1.1 \mathrm{~g} \cdot \mathrm{cm}^{-3}$. The carrier fluid is clean water.

\section{Results and Discussions}

In this paper, the effects of the particle size combination, pumping displacement, and adding sequence on the migration and settlement of temporary plugging particles in horizontal wellbore were mainly considered. The concentration of temporary plugging particles in the experiment was $1 \%$. In this paper, first, the law of the migration and settlement of temporary plugging particles in wellbore and perforations is investigated. Then, by counting the settlement mass of particles in different clusters or perforations under different conditions, the settlement laws of temporary plugging particles in horizontal wellbore and perforations are quantitatively analyzed.

\subsection{The Migration Law of Temporary Plugging Particles.} Figures 3(a)-3(c) show the migration of $3 \mathrm{~mm}$ particles in the horizontal wellbore. The pump displacement is $0.11 \mathrm{~m}^{3} \cdot \mathrm{min}^{-1}$. It can be seen that the particles are divergent when they first enter the wellbore and then quickly settle at
TABLE 1: Parameters of multicluster perforating experiment device for horizontal wells.

\begin{tabular}{lc}
\hline Parameters & Value \\
\hline The inner diameter of the wellbore $(\mathrm{mm})$ & 60 \\
The length of the wellbore $(\mathrm{m})$ & 1.5 \\
The number of the perforations & 6 \\
The clusters of the perforations & 2 \\
The inner diameter of the perforations $(\mathrm{mm})$ & 10 \\
The distance between the perforations $(\mathrm{m})$ & 0.1 \\
The distance between the clusters $(\mathrm{m})$ & 0.4 \\
\hline
\end{tabular}

the bottom of the wellbore due to their large mass. At C1, the particles move forward in a jumping way, and the fluctuation height of the particles is larger. At C2, the particles roll forward along the bottom of the wellbore, and the fluctuation height of the particles is low. The reason for this phenomenon is that the inlet velocity is large and the outlet velocity is small.

Figures 4(a)-4(c) show the migration of $1 \mathrm{~mm}$ particles in the horizontal wellbore. The experiment shows that the particles are disordered and divergent when they first enter the wellbore and then gradually move forward in layered distribution. Particles are sparse and few in the upper of the wellbore, and dense and numerous in the bottom of the wellbore. Because the $1 \mathrm{~mm}$ particles are light, it is difficult to settle when entering the wellbore, but the velocity along the wellbore gradually decreases, the particles gradually settle to the bottom of the wellbore, and some particles settle into the perforations.

Figures 5(a)-5(c) show the migration of the $3 \mathrm{~mm}$ and $1 \mathrm{~mm}$ particles in the horizontal wellbore. The results show that the migration trajectory of the two particle sizes is basically the same as the migration trajectory in the presence of a single particle size. It can be found that $3 \mathrm{~mm}$ particles always settle at the bottom of the perforation, while $1 \mathrm{~mm}$ particles cover the top of the $3 \mathrm{~mm}$ particles (Figure 5(d)). This is because $3 \mathrm{~mm}$ particles have a large mass and can 


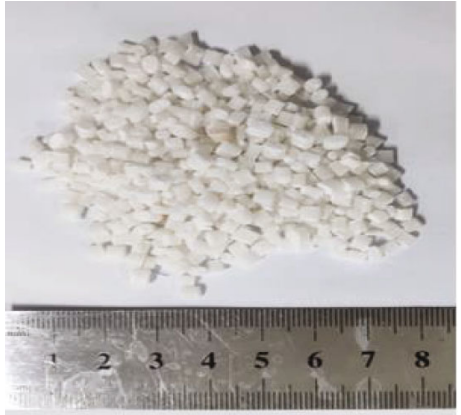

$3 \mathrm{~mm}$ particles

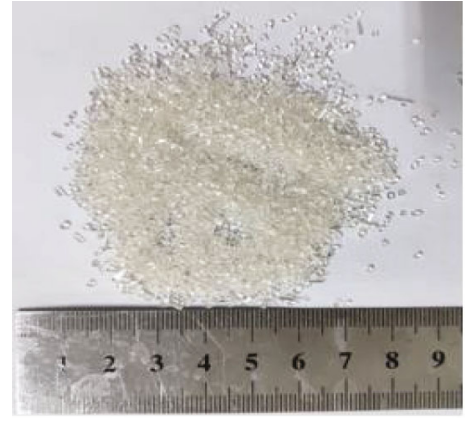

$1 \mathrm{~mm}$ particles

Figure 2: $3 \mathrm{~mm}$ particles (left) and $1 \mathrm{~mm}$ particles (right).

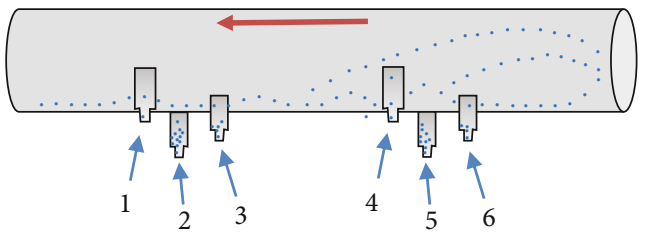

(a)

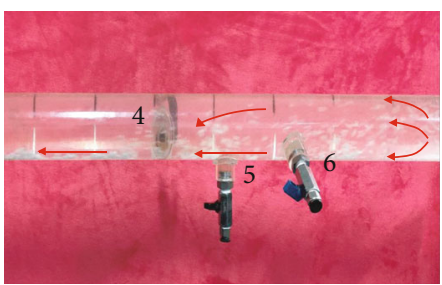

(b)

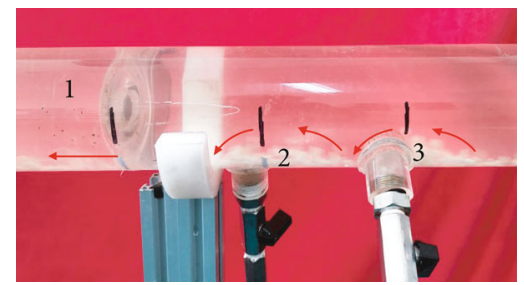

(c)

FIGURE 3: The migration trajectory of particles in the $3 \mathrm{~mm}$ temporary plugging agent wellbore; (a) schematic diagram of the particle migration; (b) particle migration trajectory at $\mathrm{C} 1$; (c) particle migration trajectory at $\mathrm{C} 2$.

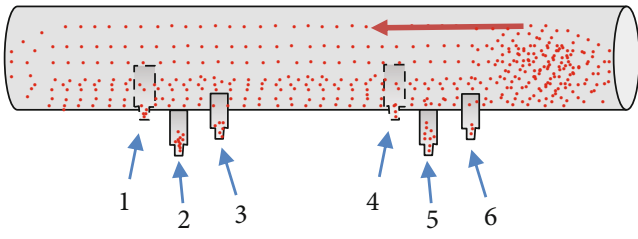

(a)

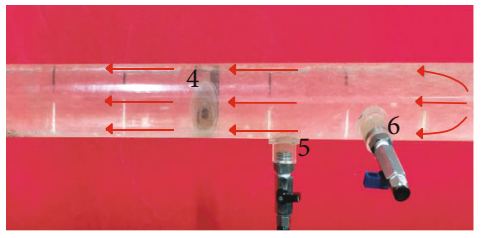

(b)

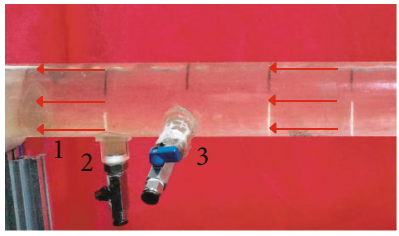

(c)

FIGURE 4: Migration trajectory in the wellbore of $1 \mathrm{~mm}$ temporary plugging agent. (a) Schematic diagram of the particle migration. (b) Particle migration trajectory at C1. (c) Particle migration trajectory at C2.

settle quickly, while $1 \mathrm{~mm}$ particles are light and have a slow settlement speed.

3.2. The Influence of Different Mass Ratio. The mass ratio is the ratio of the mass of $3 \mathrm{~mm}$ particles to $1 \mathrm{~mm}$ particles. In order to explore the migration and settlement laws of temporary plugging particles in horizontal wellbore under different mass ratios, three sets of experiments were designed (Table 2).

Figure 6(a) shows the total mass of settling temporary plugging particles in $\mathrm{C} 1$ and $\mathrm{C} 2$ under different mass ratios. The results show that the settlement mass of particles in the $\mathrm{C} 2$ is greater than that in the C1 under different mass ratios. In addition, it is found that the settlement mass of particles in $\mathrm{C} 1$ and $\mathrm{C} 2$ when the mass ratio is $5: 1$ is greater than that in other mass ratios. The reason is that the probability of their settlement in the perforation increases when the $3 \mathrm{~mm}$ particles increase. The larger the space occupied by the $3 \mathrm{~mm}$ particles in the perforation, so the greater the total settlement mass.
Figure 6(b) shows the settlement mass of particles in each perforation under different mass ratios, in which blue represents each perforation in $\mathrm{C} 1$ and orange represents each perforation in $\mathrm{C} 2$. The experimental results reveal that the settlement mass of temporary plugging particles in the vertical downward perforations $\left(0^{\circ}, \mathrm{P} 2\right.$, and $\left.\mathrm{P} 5\right)$ under different mass ratios is the largest, followed by the settlement mass of particles in the $60^{\circ}$ (P3 and P6) perforations, and the settlement mass of the particles in the $75^{\circ}(\mathrm{P} 1$ and $\mathrm{P} 4)$ perforations is the smallest. This is because most of the $3 \mathrm{~mm}$ particles jump and roll forward at the bottom of the wellbore. Therefore, the probability of particles entering in low angle perforations is high, and the settlement mass is correspondingly large.

For the same perforation, the settlement mass becomes greater as the proportion of $3 \mathrm{~mm}$ increases. This is because the $3 \mathrm{~mm}$ particles are mainly transported by jumping-rolling, and the probability of $3 \mathrm{~mm}$ particles entering the perforation increases, so the settlement mass increases. In 


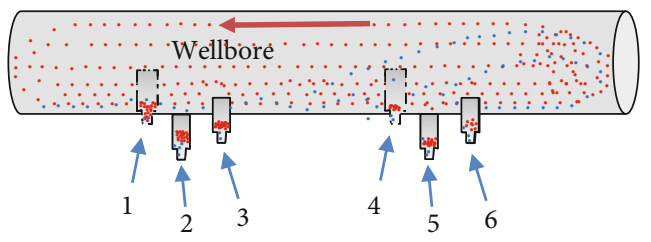

(a)

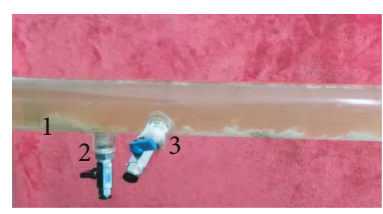

(c)

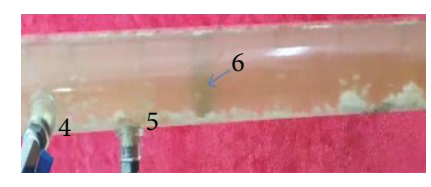

(b)

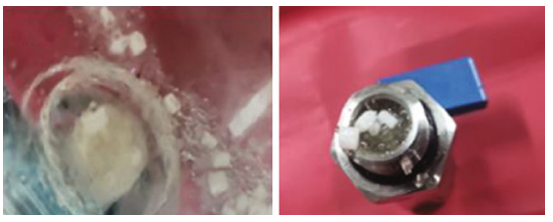

(d)

Figure 5: The migration trajectory in the wellbore of $3 \mathrm{~mm}$ and $1 \mathrm{~mm}$ mixed particles. (a) Schematic diagram of particles migration. (b) Particles migration trajectory at C1. (c) Particles migration trajectory at C2. (d) Settling of mixed temporary plugging particles in the perforation.

TABLE 2: Multiple particle size combination experiment scheme.

\begin{tabular}{lc}
\hline Mass ratio $\left(m_{3 \mathrm{~mm}}: m_{1 \mathrm{~mm}}\right)$ & Displacement $\left(\mathrm{m}^{3} \cdot \mathrm{min}^{-1}\right)$ \\
\hline $3: 3$ & 0.11 \\
$4: 2$ & \\
$5: 1$ & \\
\hline
\end{tabular}

addition, the distribution of sedimentation mass in each perforation is more concentrated when $3 \mathrm{~mm}$ particles increase.

3.3. The Influence of the Pump Displacement. The pumping displacement is one of the important factors affecting the migration of temporary plugging particles in the wellbore. With a large displacement, the temporary plugging particles tend to migrate in suspension, and the migration distance is longer; at a small displacement, the temporary plugging particles mostly move by pulsation and rolling, and the migration distance is short. The settlement of temporary plugging particles can be controlled by changing the pumping displacement. The particle size in the experiment is $3 \mathrm{~mm}$, and the experimental scheme is shown in Table 3 .

Figure 7(a) shows the settlement mass of temporary plugging particles in each cluster under different displacements. The results show that the settlement mass of temporary plugging particles in $\mathrm{C} 2$ is greater than that in $\mathrm{C} 1$, even though the displacement is different. Comparing the settlement mass of the particles in different clusters, it is found that the mass of the temporary plugging particles in $\mathrm{C} 1$ becomes larger with the increasing of the displacement. This is explained as the probability of particles collision increases when the displacement increases, which will relatively increase the probability of particles entering the perforations at the entrance; in addition, the mass of temporary plugging particles in C2 tends to increase with the decreasing of the pumping displacement, which is believed to be that the lower the displacement is, the slower the movement speed of temporary plugging particles at the bottom of wellbore is, and the fuller the settlement is, so the larger the mass is.
Figure 7(b) shows the settlement mass of temporary plugging particles in each perforation under different displacements. It can be found that the settlement mass of temporary plugging particles in the perforation is the largest when the perforations are vertically downward (angle is $0^{\circ}$ ). When the perforation angle is $60^{\circ}$, the particle settlement mass is second. When the perforation angle is $75^{\circ}$, the particle settlement mass is the lowest. An interesting finding is that the mass distribution of temporary plugging particles has an obvious ladder (green circle) in perforations with different angles, which indicates that the perforation angle has a significant impact on the settlement of temporary plugging particles under the experimental conditions. With the increasing of displacement, the sedimentation mass of particles in P1 and P4 decreases, while the sedimentation mass in other perforations increases.

3.4. The Influence of Adding Order. The adding sequence of temporary plugging particles with different particle sizes is an influential factor which attracts much attention in the field. Experimental results show that different order of addition has great influence on the settlement law of temporary plugging particles in the hole. The experimental scheme is shown in Table 4. In this group of experiments, temporary plugging particles of a certain size should be added slowly in sequence and stirred while adding, until the circulation is stable, and then the particles of another size are added, and the phenomenon is observed after being stabilized again.

Figure 8 (a) shows the settlement mass of temporary plugging particles in the clusters under different addition sequences. The results show that the settlement mass of the particles in $\mathrm{C} 2$ is larger than that in $\mathrm{C} 1$ regardless of the addition sequence. However, the difference of the settlement mass between the two clusters is nearly one time when the addition sequence is first $3 \mathrm{~mm}$ and then $1 \mathrm{~mm}$, and the difference of the settlement mass between the two clusters is small when the addition sequence is first $1 \mathrm{~mm}$ and then $3 \mathrm{~mm}$. In addition, for the outlet end, the particle settlement mass in the order of first $3 \mathrm{~mm}$ and then $1 \mathrm{~mm}$ is greater than that of the particles settlement mass in the order of first 


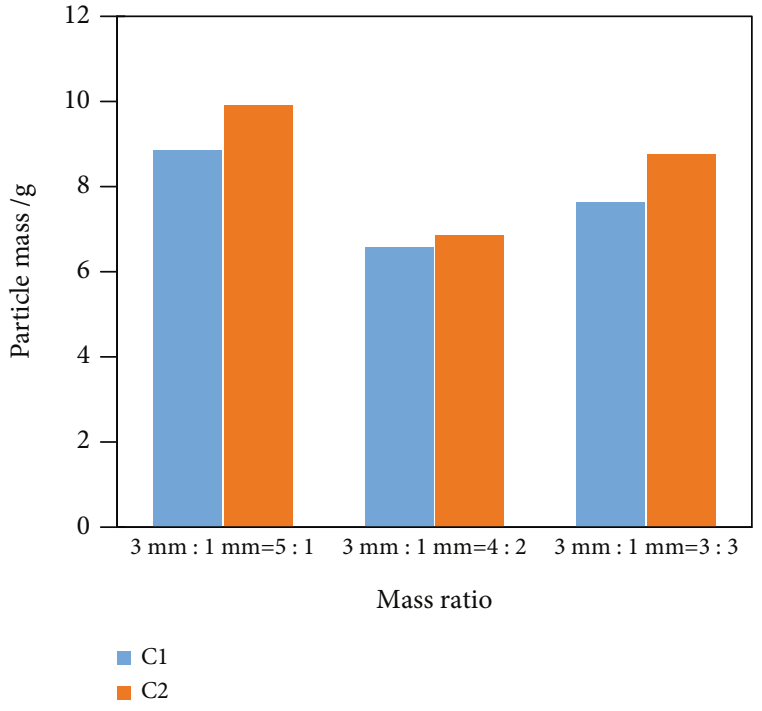

(a)

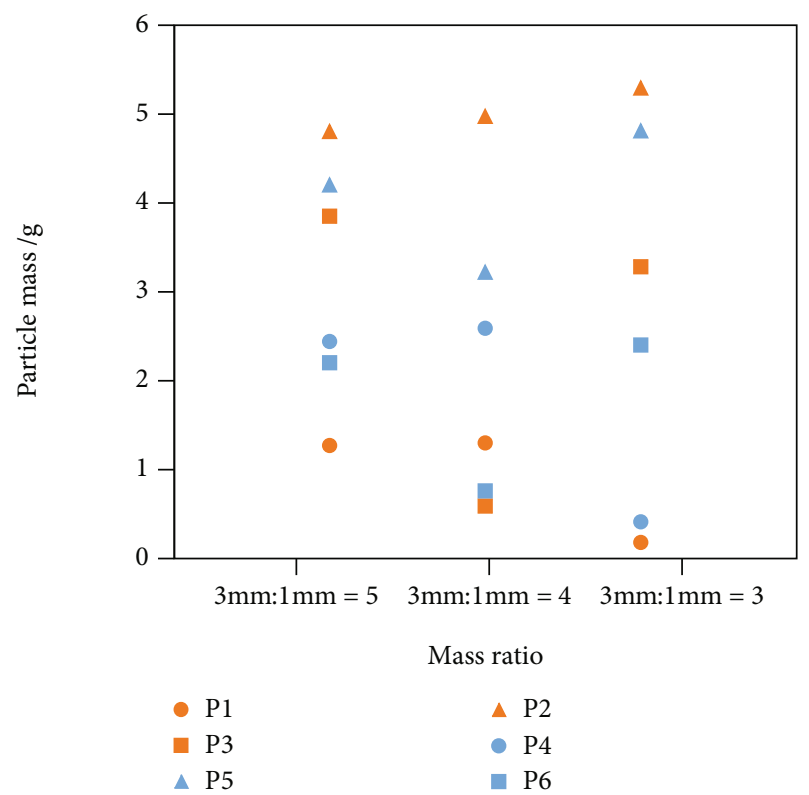

(b)

FIGURE 6: Settling mass of particles with different mass ratios in each cluster (a) and perforation (b) (orange red is the perforation at the outlet end, blue is the perforation at the inlet end, and $\mathrm{P}$ represents the perforation).

TABLE 3: Variable displacements experiment scheme table.

\begin{tabular}{cc}
\hline Particles size $(\mathrm{mm})$ & Pump displacement $\left(\mathrm{m}^{3} \cdot \mathrm{min}^{-1}\right)$ \\
\hline \multirow{3}{*}{3} & 0.11 \\
& 0.10 \\
& 0.09 \\
& 0.08 \\
\hline
\end{tabular}

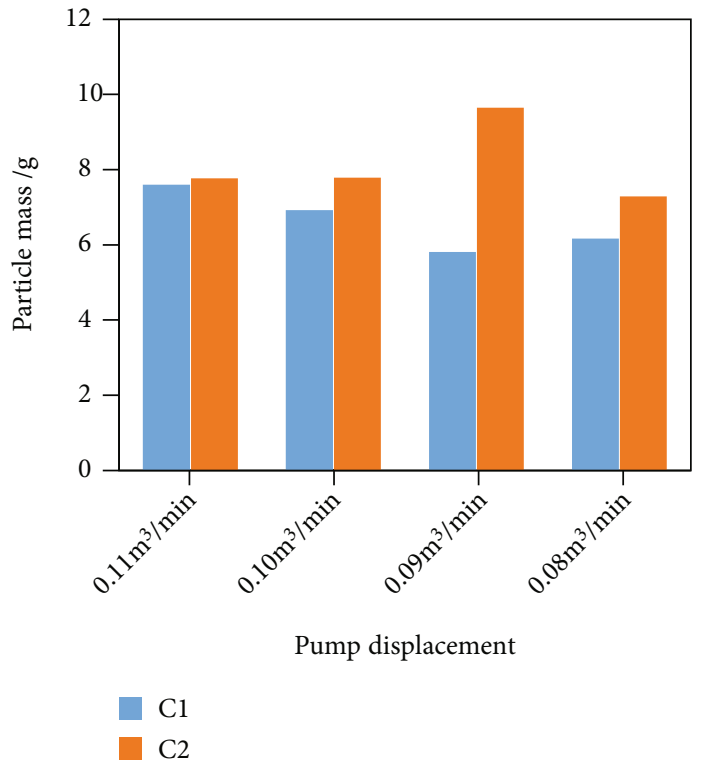

(a)

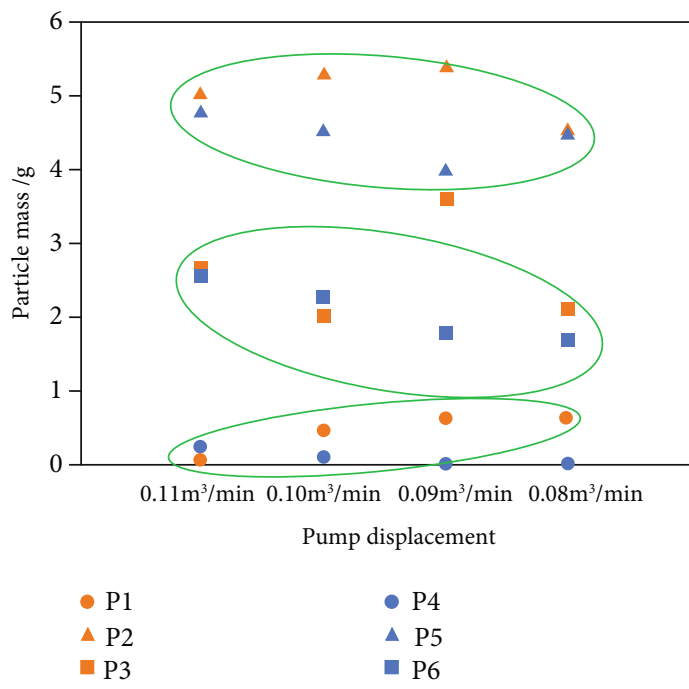

(b)

FIgURE 7: The settlement mass of the temporary plugging particles in each cluster (a) and perforation (b) under different pump displacements (orange red is the perforation at the outlet end, blue is the perforation at the inlet end, and $\mathrm{P}$ represents the perforation).

TABle 4: Add sequence experiment scheme.

\begin{tabular}{lcc}
\hline Adding order & $\begin{array}{c}\text { Particle } \\
\text { concentration }(\%)\end{array}$ & $\begin{array}{c}\text { Pump displacement } \\
\left(\mathrm{m}^{3} \cdot \mathrm{min}^{-1}\right)\end{array}$ \\
\hline $\begin{array}{l}\text { First } 1 \mathrm{~mm} \text { then } \\
3 \mathrm{~mm}\end{array}$ & 1 & 0.11 \\
$\begin{array}{l}\text { First } 3 \mathrm{~mm} \text { then } \\
1 \mathrm{~mm}\end{array}$ & 1 & \\
\hline
\end{tabular}




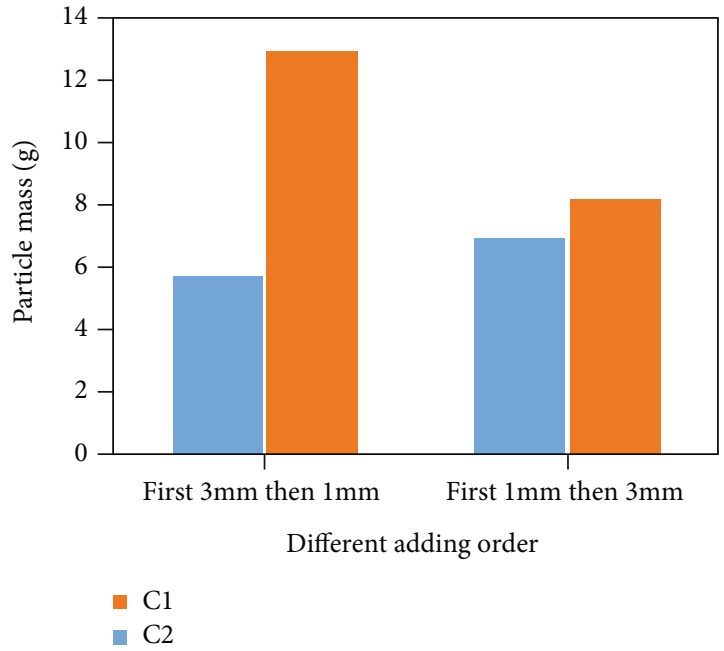

(a)

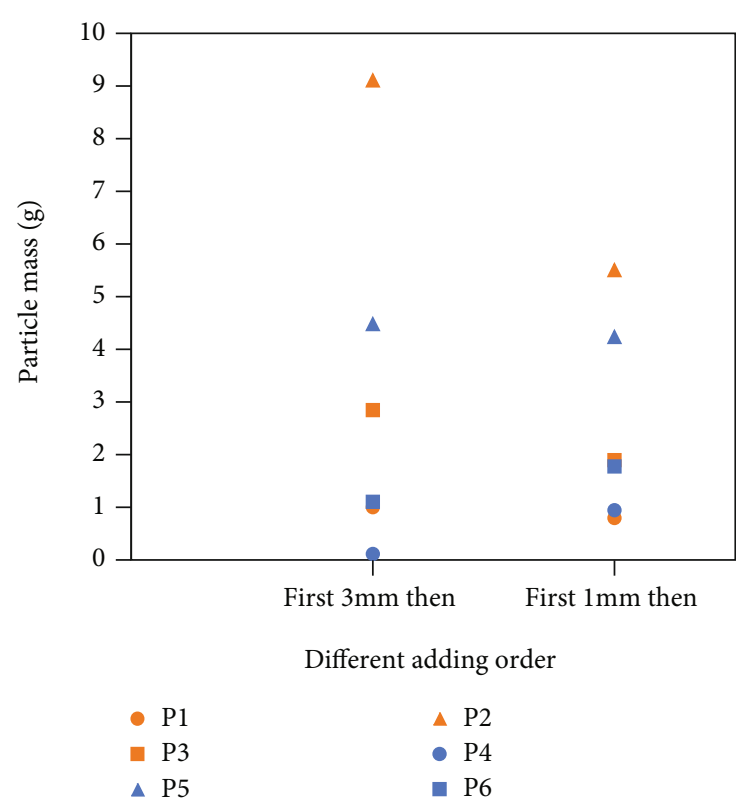

(b)

Figure 8: Settlement mass of temporary plugging particles in clusters (a) and perforations (b) under different adding order.

$1 \mathrm{~mm}$ and then $3 \mathrm{~mm}$. This is because $3 \mathrm{~mm}$ particles are added first, which can settle quickly and fill most of the perforation space first, while $1 \mathrm{~mm}$ particles can only fill the remaining small gaps.

Figure 8(b) shows the settlement mass of temporary plugging particles in the perforations under different addition sequences. It can also be found that the settlement mass of temporary plugging particles reaches the maximum when the perforation angle is $0^{\circ}$. When the perforation angle is $60^{\circ}$, the particle settlement mass is second. When the perforation angle is $75^{\circ}$, the particle settlement mass is the lowest. At the same time, it is found that the mass distribution of temporary plugging particles in each perforation is larger when the addition sequence is first $3 \mathrm{~mm}$ and then $1 \mathrm{~mm}$. However, the mass distribution range of temporary plugging particles in each perforation is relatively concentrated when the addition sequence is first $1 \mathrm{~mm}$ and then $3 \mathrm{~mm}$.

\section{Conclusions}

Based on the visual horizontal wellbore experiment device, the migration and settlement laws of temporary plugging particles in the wellbore were investigated, and the following conclusions were drawn:

(1) The $3 \mathrm{~mm}$ temporary plugging particles move forward in a jumping way at the bottom of the horizontal wellbore. The $1 \mathrm{~mm}$ particles move forward in horizontal layered distribution inside the horizontal wellbore, and the particles are sparse and few in the upper layer of the horizontal wellbore, and dense and numerous in the bottom layer of the wellbore. The migration trajectory of the $3 \mathrm{~mm}$ and $1 \mathrm{~mm}$ particles mixed in the horizontal wellbore is basically the same as that of the single particle size
(2) Considering the factors of mass ratio, displacement, and addition sequence, the settlement mass of the temporary plugging particles in the outlet $\mathrm{C} 2$ is greater than that in the inlet $\mathrm{C} 1$

(3) The smaller the perforation angle is, the larger the settlement mass of temporary plugging particles is. When the perforation angle is $0^{\circ}$, the settlement mass of temporary plugging particles in the perforation is the largest. When the perforation angle is $60^{\circ}$, the particle settlement mass is second. When the perforation angle is $75^{\circ}$, the particle perforation angle is the lowest

(4) Under different particle mass ratios, the settlement mass of particles in outlet $\mathrm{C} 2$ is larger than that in inlet C1. When $m_{3 \mathrm{~mm}}: m_{1 \mathrm{~mm}}=5: 1$, the mass of particle sedimentation is the largest. With the increase of pump displacement, the mass of temporary plugging particles in $\mathrm{C} 1$ increases, while the mass of temporary plugging particles in $\mathrm{C} 2$ decreases with the increase of pump displacement. As the displacement increases, the sedimentation mass of particles in P1 and P4 decreases, and the sedimentation mass in the remaining perforations increases. In C2, the settlement mass of temporary plugging particles in the sequence of adding $3 \mathrm{~mm}$ first and $1 \mathrm{~mm}$ later is greater than that in the sequence of adding $1 \mathrm{~mm}$ first and $3 \mathrm{~mm}$ later

(5) The larger the displacement, the sedimentation mass of particles in P1 and P4 decreases, and the sedimentation mass in the remaining perforations increases. In general, the larger the displacement, the greater the sedimentation mass in the perforation; the greater the ratio of $3 \mathrm{~mm}$, the greater the particle sedimentation mass 


\section{Data Availability}

The chart data used to support the findings of this study are included within the article.

\section{Conflicts of Interest}

The authors declare that they have no conflicts of interest.

\section{Acknowledgments}

The authors would like to acknowledge the financial support from the Oilfield technical services funding (no. HX20191217).

\section{References}

[1] Y. Wang, Y. Lu, Y. Li, and X. Wang, "Progress and application of unconventional reservoir fracturing technology," Acta Petrolei Sinica, vol. 33, no. 1, pp. 149-158, 2012.

[2] Z. Jinzhou, Z. Jin, H. Yongquan, H. Ting, and L. Xinjia, "Variation rule of fracture stress field in hydraulic fracturing," Natural Gas Geoscience, 2019, vol. 30, no. 12, pp. 1677-1683, 2019.

[3] Z. Jin, Z. Suian, M. Dongmin et al., "Numerical simulation of enhancing CBM recovery by $\mathrm{CO} 2$ injection," Natural Gas \& Oil, vol. 6, no. 1, pp. 67-70, 2012.

[4] G. Peifeng, Z. Wen, D. Hucheng, X. Yang, P. Xianfeng, and D. Yong, "True triaxial physical simulation experiment and fracture extension rule of tight reservoir fracturing," Journal of Chengdu University of Technology (Science \& Technology Edition), vol. 47, no. 1, pp. 65-74, 2020.

[5] P. Xiao, "Analysis of temporary plugging particles in fracturing and its application scope," Petrochemical Industry Application, vol. 37, no. 10, pp. 9-13, 2018.

[6] G. G. Stokes, On the Effect of the Internal Friction of Fluids on the Motion of Pendulums, Transactions of the Cambridge Philosophical Society, 1851.

[7] D. E. McMechan and S. N. Shah, Proppant-Settlement Correlation of Non-Newtonian Fluids, SPE Production Engineering, 1991.

[8] R. S. Schols and W. Visser, "Proppant bank buildup in a veritical fracture without fluid loss," in SPE European Spring Meeting, vol. 4834, Amsterdam, Netherlands, 1974.

[9] P. E. Clark, M. W. Harkin, H. A. Wahl, and J. A. Sievert, "Design of a large vertical prop transport model," in SPE Annual Fall Technical Conference and Exhibition, vol. 6814, 1977Denver, Colorado.

[10] J. A. Sievert, H. A. Wahl, P. E. Clark, and M. W. Harkin, Proppant Transport in a Large Vertical Model, Society of Petroleum Engineers (SPE), 1981.

[11] Y. Xu and C. Zhou, "Calculation of critical settlement velocity of horizontal well fracturing," Journal of Xi 'an Petroleum Institute, vol. 2, pp. 19-21, 1995.

[12] R. R. Hannah, L. J. Harrington, and R. W. Anderson, "Measurement of dynamic proppant fall rates in fracturing gels using a concertric cylinder tester," Journal of Petroleum Technology, vol. 7571, 1978.

[13] L. J. Harrington, R. R. Hannah, and D. Williams, "Dynamic experiments on proppant settling in crosslinked fracturing fluids," in SPE Annual Technical Conference and Exhibition, p. 8342, Las Vegas, Nevada, 1979.
[14] E. J. Novotny, "Proppant transport," in SPE Annual Fall Technical Conference and Exhibition, vol. 6813, Denver, Colorado, 1977.

[15] P. E. Clark, F. S. Manning, J. A. Quadir, and N. Guler, "Prop transport in vertical fractures," in SPE Annual Technical Conference and Exhibition, vol. 10262, p. 1981, San Antonio, Texas, 1981.

[16] J. A. Quadir, Particle Tranport by Non-Newtonian Fluids in Vertical Slots, The University of Tulsa, 1981.

[17] M. M. Sharma and P. B. Gadde, "The impact of proppant retardation on propped fracture lengths," in SPE Annual Technical Conference and Exhibition, Dallas, Texas, 2005.

[18] A. Bokane, S. Jain, Y. Deshpande, and F. Crespo, "Transport and distribution of proppant in multistage fractured horizontal wells: a CFD simulation approach," SPE annual technical conference and exhibition, 2013, New Orleans, Louisiana, USA, 2013, 2013.

[19] F. Crespo, N. K. Aven, J. Cortez et al., "Proppant distribution in multistage hydraulic fractured wells: a large-scale insidecasing investigation," SPE hydraulic fracturing technology conference, 2013, The Woodlands, Texas, USA, February 2013 , 2013.

[20] K. L. Ngameni, Proppant Transport in Horizontal Wellbores Using Fresh Water, Colorado School of Mines, Golden, 2016.

[21] T. Zhang, J. C. Guo, and W. Liu, "CFD simulation of proppant transportation and settling in water fracture treatments," Journal of Southwest Petroleum University: Science \& Technology Edition, vol. 36, no. 1, pp. 74-82, 2014.

[22] G. D. Zhang, Research on Proppant Transport Affected by Multiple Mechanisms during Horizontal Well Fracturing, China University of Petroleum (East China), 2017.

[23] P. Linhua, Z. Ye, L. Zhaohui et al., "A kind of proppant migration and settlement in horizontal wellbore," The simulation device of shunt: CN201821280850.1, 2019.

[24] S. Mao, P. Siddhamshetty, Z. Zhang et al., "Impact of proppant pumping schedule on well production for slickwater fracturing," SPE Journal, vol. 26, no. 1, pp. 342-358, 2020.

[25] L. K. Britt, M. B. Smith, Z. A. Haddad, J. P. Lawrence, S. T. Chipperfield, and T. J. Hellman, "Waterfracs: we do need proppant after all," in SPE Annual Technical Conference and Exhibition, San Antonio, Texas, USA, 2006. 